\title{
A contribution to the validation of the Italian version of the Body Image Scale (BIS)
}

\author{
Maria Antonietta Annunziata ${ }^{*}{ }^{+}$, Barbara Muzzatti ${ }^{\dagger}$, Francesca Bomben, Cristiana Flaiban, Marika Piccinin and \\ Valentina Solfrini
}

\begin{abstract}
Background: The Body Image Scale (BIS) is a 10-item mono-factorial scale, designed to capture distress and symptoms related to body image in cancer patients. This paper describes the conversion and psychometric evaluation of an Italian BIS version.

Methods: After the back-translation procedure, the Italian version of the BIS, together with the Hospital Anxiety and Depression Scale and the Short Form 36 Health Survey Questionnaire, have been administered to a sample of Italian adult females, surgically treated for a breast cancer at least one year before.

Results: Data on 109 participants were analyzed. The response rate was 92.5\%. Response prevalence was adequate for 9 out of 10 items. Principal component analysis showed a one-factor structure. Internal consistency (Cronbach's alpha $=0.924)$ was good. The BIS correlated with the theoretically pertinent subscales of the other administered tools and was able to discriminate participants (discriminant validity) according to the undertaken surgical treatment $(p=0.031)$.
\end{abstract}

Conclusions: This study supports the valid and reliable use also of the Italian version of the BIS.

Keywords: Body image, Body image scale, Oncology, Psychometrics, Validation

\section{Background}

"Body image" is an individual and composite experience through which people relate to their our body; it depends on many factors including gender, age, physical and mental functioning [1].

The Body Image Scale (BIS, [2]) was developed in England to capture distress and symptoms related to body image in cancer patients. It is a 10-item mono-dimensional scale suitable in oncological settings, regardless of patients' diagnosis, treatment or disease stages. Respondents answer each item using a 4-point rating scale where Score 0 corresponds to "not at all", Score 1 corresponds to "a little", Score 2 corresponds to "quite a bit" and Score 3 corresponds to "very much". Items' scores are summed to obtain a total score with higher scores corresponding to higher symptoms/distress. Good psychometric properties were

\footnotetext{
* Correspondence: annunziata@cro.it

${ }^{\dagger}$ Maria Antonietta Annunziata and Barbara Muzzatti contributed equally to this work.

Centro di Riferimento Oncologico di Aviano (CRO), IRCCS, 33081 Aviano, Italy
}

reported in its first validation study [2]. Data on BIS validity and reliability have also been provided for its Portuguese [3], Korean [4], Thai [5], Dutch [6], Spanish [7], and Turkish [8] versions, as well as in studies involving ostomy patients [8], patients undergoing surgery for colorectal cancer [9], or women with benign gynecological conditions [10]. To our knowledge, no studies have been published reporting the validation of BIS for Italian patients [11].

This paper aimed to describe the translation and psychometric validation of an Italian version of the BIS. Our findings will be useful in the Italian national context as it provides an internationally well-known body image assessment tool; at the same time, it will play a role in the in-depth examination of the BIS psychometric properties from a cross-cultural perspective.

\section{Method \\ Participants}

Data used for the present study derived from a larger prospective study designed to describe QoL and 
psychological well-being of breast cancer patients within a month from the cancer diagnosis, and one and two years after it. All participants were adult female breast cancer patients, had to understand the Italian language and signed the informed consent. In addition, a further inclusion criterion for the present study was to have been surgically treated for breast cancer one year before.

\section{Procedure and materials}

BIS was translated into Italian by back translation procedure: two Italian, English proficient, psychology researchers translated the BIS into Italian; then, the two Italian translations were compared and compiled into a single preliminary version; and finally re-translated into English by a professional translator. The final Italian version was achieved by revision of the preliminary one according to the results of the comparison of the original version of the scale and its re-translation into English from Italian.

The final Italian version of BIS is available as an (Additional file 1).

Italian BIS version was administered to participants together with the Hospital Anxiety and Depression scale (HADS, [12]), the Short Form 36 Health Survey Questionnaire (SF-36, [13]), and a form to collect socio-demographic and clinical data.

All participants received materials at home as the second step of a larger study, with the instruction to fill out and return them by mail (a pre-paid envelope was provided together with the study booklet) within 3 weeks.

The Institute Independent Ethics Committee gave its clearance to the study.

HADS is a self-report scale assessing anxious and depressive states of medical patients. It is made up of two factors, in which higher scores correspond to higher anxious and depressive states respectively. Validation data for Italian HADS version were provided by Annunziata et al. [14].

The SF-36 is a QoL measure consisting of 36 items and eight different QoL indices: Physical Functioning, Role-Physical Limitation, Bodily Pain, General Health, Vitality, Social Functioning, Role-Emotional Limitation, Mental Health. In each index, higher scores indicate better functioning in that domain. Validation for SF-36 Italian version was provided by Apolone et al. [15].

Socio-demographic and clinical data were self-reported and collected information on age, marital status, education, occupational status, and cancer treatments.

\section{Statistical analysis}

Feasibility of BIS was assessed by response rates and missing answers.
Response prevalence was defined as the frequency of positive ratings (score $>0$ ) for each item, indicating some change in body image; $30 \%$ of positive ratings of the total sample in each item was used as criterion.

To assess the factor structure, a principal component analysis (PCA) was performed. Scree plots, the number of eigenvalues exceeding 1 and the percentage of explained variance were used in determining the number of extracted factors. Only items with factor loadings of 0.40 or above were retained.

Internal consistency was assessed using Cronbach's Alpha; scores exceeding 0.70 have been considered acceptable [16].

The convergent/divergent validity was assessed by Spearman's correlations with the subscales of the HADS and SF-36: rho $<0.30,0.30<r h o<0.45,0.45<r h o<0.60$, and rho $>0.60$ have been considered indices of a negligible, moderate, substantial, and high correlation, respectively [17].

The discriminant validity was assessed comparing BIS score according to the type of received surgery (quadrantectomy vs. mastectomy) through an independent sample t-test.

Descriptive statistics (mean, standard deviation, minimum, maximum) were calculated for the entire scale as well as for each item in this sample.

All analyses were performed on the subsample who had provided a complete BIS; an exception was made for feasibility which was assessed using all provided BIS.

In all analyses, $p<0.05$ (2-tailed) was used for statistical significance. The Statistical Package for the Social Sciences (SPSS) was used to perform the analyses.

\section{Results}

\section{Sample characteristics}

Study materials were sent to 120 participants of whom, nine $(7.5 \%)$ did not respond. After exclusion of two participants (one with missing response on BIS and another with two missing responses, 1.7\%), 109 participants were included in the dataset. The median age of the final sample was 42 years (range: 26-46). 83.3\% participants reported a post-compulsory education (i.e., more than 8 years of schooling); $76.1 \%$ reported to be in a stable relationship (i.e., being married or cohabiting); and $80.8 \%$ reported having a paying job. $53.2 \%(N=58)$ of the sample had received quadrantectomy 1 year before, $42.2 \%(N=46)$ mastectomy, and $4.6 \% \quad(N=5)$ mastectomy and breast reconstruction.

\section{Feasibility}

The response rate was $92.5 \%$.

There was one $(0.9 \%)$ missing answer in BIS for item 5 , and two (1.8\%) missing answers for item 8 . No other missing data were present. 


\section{Response prevalence}

The frequency of positive ratings for each item ranged from $56 \%$ of both Item 3 and 10 , to $89 \%$ for Item 6 ; the only exception was item 7 , for which the frequency of positive ratings was $27.5 \%$.

\section{Factor structure}

Factor structure was assessed by PCA. Before performing it, data suitability for factoring was verified. Inspection of the correlation matrix revealed the presence of many coefficients of 0.30 and above. Both the Kaiser-Meyer-Oklin value and the Bartlett's test of sphericity $(p<0.001)$, supported the factorability of the correlation matrix.

PCA revealed the presence of one factors with Eigenvalues exceeding 1 , supported by inspection of the scree plot (available as Additional file 2). All items loaded on one component at 0.60 or above, and this solution explained a total of $60.1 \%$ of the total variance.

\section{Internal consistency}

Cronbach's Alpha was equal to 0.924 in the present sample.

\section{Convergent/divergent validity}

Table 1 shows the correlations of the BIS scores with the scores of the HADS and SF-36.

BIS showed a substantial correlation with the subscale Depression of the HADS (positive correlation) and with the subscale Mental Health of SF-36 (negative correlation). In addition, it correlated moderately with the subscale Anxiety of the HADS (positive correlation) and with the SF-36 subscales: Role-Physical Limitation, General Health, Vitality,

Table 1 Spearman's correlations of BIS - Italian version with HADS and SF-36 $N=109$ )

\begin{tabular}{lll}
\hline & BIS & \\
\cline { 3 - 3 } & Rho & \\
\hline HADS & & \\
Anxiety & 0.416 & 0000 \\
Depression & 0.493 & 0.000 \\
SF-36 & & \\
Physical functioning & -0.277 & 0.003 \\
Role-physical limitation & -0.307 & 0.001 \\
Bodily pain & -0.213 & 0.026 \\
General health & -0.363 & 0.000 \\
Vitality & -0.432 & 0.000 \\
Social functioning & -0.433 & 0.000 \\
Role-emotional limitation & -0.332 & 0.000 \\
Mental health & -0.452 & 0.000 \\
\hline
\end{tabular}

Social Functioning, Role-Emotional Limitation (negative correlation). Since higher scores in HADS correspond to higher intensity levels in the assessed negative emotional states whereas higher scores in SF-36 correspond to a better functioning in the assessed QoL domain, higher BIS scores correspond to higher levels in anxiety/depression and/or to a poorer QoL.

\section{Discriminant validity}

The subsample of females who had undertaken mastectomy displayed higher BIS scores than who had undertaken quadrantectomy $(M=12.94$ vs. $M=9.78$; $p=0.031)$.

\section{Descriptive statistics}

Table 2 displays mean, standard deviation, minimum, and maximum for BIS as a total score and for each BIS item.

\section{Discussion}

Body image is widely recognized as a critical psychosocial issue for cancer patients, with concerns about appearance and body changes varying based upon clinical features of the disease and treatment side effects $[18,19]$. Body image concerns can interfere with the disease trajectory and influence both therapeutic decisions and adherence. A negative body image can adversely impact social functioning (intimate, interpersonal relationship), general functioning and QoL during both anticancer treatment and survivorship [19].BIS is a well-known and widely used questionnaire designed to detect distress and suffering related to body image in oncological settings regardless of patients' diagnosis, treatment or disease stages [11]. Despite its popularity, no data on an Italian version were yet available. The present study described the translation into Italian and the main psychometric properties of a BIS version suitable for Italian cancer patients.

According to the present data, Italian BIS version showed appropriate feasibility, response prevalence, factorial structure, internal consistency, convergent/divergent and discriminant validity. Previous literature [3-8] has already confirmed BIS reproducibility in non-English speaking contexts, our study expanded on this by adding Italy. However, further research is necessary to complete the Italian validation of BIS, as well as to strengthen its the informative power. In fact, more studies are necessary to verify the suitability of BIS with other (than breast cancer women) Italian oncological populations. More in general, BIS ability to discriminate cases from non-cases has not been tested yet in any of the different cultural context (including the original one) in which the tool has been translated. This further step in BIS 
Table 2 Descriptive statistics for the Italian version of BIS ( $N=109)$

\begin{tabular}{|c|c|c|c|c|}
\hline & Mean & Standard deviation & Minimum & Maximum \\
\hline 1. Have you been feeling self-conscious about your appearance? & 1.12 & 0.950 & 0 & 3 \\
\hline 2. Have you felt less physically attractive as a result of your disease or treatment? & 1.38 & 0.998 & 0 & 3 \\
\hline 3. Have you been dissatisfied with your appearance when dressed? & 0.85 & 0.901 & 0 & 3 \\
\hline 4. Have you been feeling less feminine as a result of your disease or treatment? & 1.23 & 1.077 & 0 & 3 \\
\hline 5. Did you find it difficult to look at yourself naked? & 1.25 & 1.011 & 0 & 3 \\
\hline $\begin{array}{l}\text { 6. Have you been feeling less sexually attractive as a result of your disease or } \\
\text { treatment? }\end{array}$ & 1.61 & 0.932 & 0 & 3 \\
\hline 7. Did you avoid people because of the way you felt about your appearance? & 0.48 & 0.899 & 0 & 3 \\
\hline 8. Have you been feeling the treatment has left your body less whole? & 1.16 & 0.925 & 0 & 3 \\
\hline 9. Have you felt dissatisfied with your body? & 1.15 & 0.970 & 0 & 3 \\
\hline 10. Have you been dissatisfied with the appearance of your scar? & 0.92 & 1.020 & 0 & 3 \\
\hline Total score & 11.14 & 7.472 & 0 & 29 \\
\hline
\end{tabular}

validation will be useful to improve its clinical relevance. Finally, the present study, together with much of the previous literature on BIS, assessed its factorial structure by means of exploratory methods and, consequently, studies involving confirmatory techniques are recommended.

\section{Conclusion}

In conclusion, the current study confirms the suitability of the BIS to describe body image in Italian female breast cancer patients and represents the first Italian contribution to the validation process for this scale.

\section{Additional files}

Additional file 1: BIS Italian version, BIS, Scala di valutazione dell'immagine corporea. (PDF $124 \mathrm{~kb}$ )

Additional file 2: Scree plot. (JPG $16 \mathrm{~kb}$ )

\section{Abbreviations}

BIS: Body Image Scale; QoL: Quality of life

\section{Acknowledgements}

The Authors wish to thank Ms. Anna Vallerugo, MA, and Ms. Luigina Mei for their editorial assistance.

\section{Funding}

Data collection of this study had been supported by 5X1000_2011_MdS.

\section{Availability of data and materials}

The dataset used and analyzed during the current study is available from the corresponding author on reasonable request.

\section{Authors' contributions}

MAA planned the work, coordinated the study and contributed in manuscript preparation. BM planned the work, analyzed the data and contributed in manuscript preparation. FB collected data. CF collected data. MP collected data. VS coordinated the study. All Authors read and approved the final manuscript.

\section{Ethics approval and consent to participate}

The Ethics Committee of the IRCCS Centro di Riferimento Oncologico di Aviano gave its clearance to the present study (CRO-2009-40).
Signed informed consent was obtained by each participant before enrollment.

Consent for publication

Not applicable.

\section{Competing interests}

The authors declare that they have no competing interest.

\section{Publisher's Note}

Springer Nature remains neutral with regard to jurisdictional claims in published maps and institutional affiliations.

Received: 15 March 2018 Accepted: 27 November 2018

Published online: 06 December 2018

\section{References}

1. Cash TF, Smolak L, editors. Body image: a handbook of science, practice, and prevention. New York: Guilford Press; 2011.

2. Hopwood P, Fletcher I, Lee A, Al Ghazal S. A body image scale for use with cancer patients. Eu J Cancer. 2001;37:189-97.

3. Moreira H, Silva S, Marques A, Canavarro MC. The Portuguese version of the body image scale (BIS) - psychometric properties in a sample of breast cancer patients. Eu J Oncol Nurs. 2010;14:111-8.

4. Khang D, Rim HD, Woo J. The korean version of the body image scalereliability and validity in a sample of breast cancer patients. Psychiatry Investig. 2013;10:26-33.

5. Songtish D, Hirunwiwatkul P. Development and validation of the body image scale among Thai breast cancer patients. J Med Assoc Thail. 2013; 96(Suppl 1):S30-9.

6. van Verschuer VM, Vrijland WW, Klem TM. Reliability and validity of the Dutch-translated body image scale. Qual Life Res. 2015;24:1629-33.

7. Gómez-Campelo P, Bragado-Álvarez C, Hernández-Lloreda MJ, SánchezBernardos ML. The Spanish version of the body image scale (S-BIS): psychometric properties in a sample of breast and gynaecological cancer patients. Support Care Cancer. 2015;23:473-81.

8. Karayurt Ö, Edeer AD, Süler $G$, et al. Psychometric properties of the body image scale in Turkish ostomy patients. Int J Nurs Knowledge. 2015;26:12734.

9. Whistance RN, Gilbert R, Fayers P, et al. Assessment of body image in patients undergoing surgery for colorectal cancer. Int J Colorect Disease. 2010:25:369-74.

10. Stead ML, Fountain J, Napp V, Garry R, Brown JM. Psychometric properties of the body image scale in women with benign gynaecological conditions. Eu J Obstetric Gynecol Reproductive Biol. 2004;114:215-20.

11. Muzzatti B, Annunziata MA. Body image assessment in oncology: an update review. Support Care Cancer. 2017;25:1019-29. 
12. Zigmond AS, Snaith RP. The hospital anxiety and depression scale. Acta Psychiatrica Scandinav. 1983;67:361-70.

13. Ware JE, Snow KK, Kosinki M, Gandek B. SF-36 Health Survey-Manual and Interpretation Guide. Boston, Mass: The Health Institute; 1993.

14. Annunziata MA, Muzzatti B, Altoè G. Defining hospital anxiety and depression scale (HADS) structure by confirmatory factor analysis: a contribution to validation for oncological settings. Ann Oncol. 2011;22: 2330-3.

15. Apolone G, Mosconi P, Ware JE. Questionario sullo stato di salute SF-36, manuale d'uso e guida all'interpretazione dei risultati. Milano: Guerini e Associati; 1997.

16. Cronbach L. Coefficient alpha and the internal structure of test. Psychometrica. 195116:297-334.

17. Burnand B, Kernan WN, Feinstein AR. Indexes and boundaries for 'quantitative significance' in statistical decisions. J Clin Epidemiol. 1990;43: 1273-84.

18. Annunziata MA, Muzzatti B. Psychosocial issues in cancer care Neuropathological Diseases. 2012;1:41-56.

19. Annunziata MA, Muzzatti B, Fingeret MC. Body image assessment in oncological settings. In, MC. Fingeret \& I. Teo (Eds), Principles and practices of body image Care for Cancer Patients. New York, NY: Oxford University Press 2018, 34-55.

Ready to submit your research? Choose BMC and benefit from:

- fast, convenient online submission

- thorough peer review by experienced researchers in your field

- rapid publication on acceptance

- support for research data, including large and complex data types

- gold Open Access which fosters wider collaboration and increased citations

- maximum visibility for your research: over $100 \mathrm{M}$ website views per year

At $\mathrm{BMC}$, research is always in progress.

Learn more biomedcentral.com/submissions 